\title{
Evaluation of the Extent and Pattern of Use of Herbal Bitters among Students in a Tertiary Institution in Southwestern Nigeria
}

\author{
Showande SJ* and Amokeodo OS \\ Department of Clinical Pharmacy and Pharmacy Administration, Faculty of Pharmacy, University of Ibadan, Ibadan, Nigeria
}

*For correspondence: Email: pharmseg@yahoo.com, sj.showande@mail.ui.edu.ng; Tel: +2348027887608

Received: 22 July 2013

Revised accepted: 21 August 2014

\begin{abstract}
Purpose: To evaluate the extent and pattern of use of herbal bitters among students.

Methods: This was a cross-sectional study where pre-tested structured questionnaires were administered to 1000 students. The questionnaire elicited information on the extent and pattern of use, self-reported indications, side effects experienced and possible drugs that were concomitantly coadministered with herbal bitters. Pearson Chi square, Fisher exact test and Relative risk ratio were used to detect association between gender and self-reported indications and side effects experienced with herbal bitters at a level of significance of $p<0.05$.

Results: The response rate and extent of use were $96 \%$ and $40.9 \%$ respectively. Herbal bitters were used for claims such as cleansers 88 (40.2\%), anti-infectives 48 (21.1\%), for rejuvenation 32 (14.0\%), and for weight loss 14 (6.1\%). Self-reported side effects included dizziness 49 (22.0\%), loss of taste 46 (20.6\%) and nausea and vomiting 22 (9.7\%). Herbal bitters were also co-administered with antimalarials 22 (6.3\%); analgesics 16 (4.5\%) and herbal supplements 13 (3.7\%). Reports of students using two different types of herbal bitter concurrently 15 (3.9\%) were also garnered. Male students experienced more side effects than females $(p<0.05)$.

Conclusion: The co-administration of herbal bitters with allopathic medicines and the use of more than one herbal bitter at a time reported in this study can be addressed by the appropriate health authorities through proper educational programme.
\end{abstract}

Keywords: Herbal bitters, Allopathic medicines, Students, Advertisement, Nigeria

\begin{abstract}
Tropical Journal of Pharmaceutical Research is indexed by Science Citation Index (SciSearch), Scopus, International Pharmaceutical Abstract, Chemical Abstracts, Embase, Index Copernicus, EBSCO, African Index Medicus, JournalSeek, Journal Citation Reports/Science Edition, Directory of Open Access Journals
\end{abstract} (DOAJ), African Journal Online, Bioline International, Open-J-Gate and Pharmacy Abstracts

\section{INTRODUCTION}

Africa traditional healers have used herbal medicines to treat diverse ailments with relative success before the advent of allopathic medicines. This practice gradually waned with the development of synthetic drugs; however, there has been resurgence in the use of herbal medicines all over the world including subSaharan Africa [1]. Self-treating illnesses with herbal medicine is encouraged by belief in local complementary and alternative medicines (CAM) such as acupuncture, chiropractic manipulation, meditation, homeopathy, Ayurveda and traditional medicines like "Agbo" and herbal bitters (HB) in Nigeria [2].

Eighty percent of people in developing countries rely on herbal medicines for self-treating different ailments [3]. Herbal medicines are readily available in health shops; the increase in their use, either alone or in combination with allopathic 
medicines is augmented by the belief that all herbal medicines are safe [4]. Although, unlicensed in many countries, in Nigeria, the National Agency for Food Drug Administration and Control (NAFDAC) recognises these products and approves them for sales [5]. Coupled with the approval given by NAFDAC there is unrestrained advertisement of these products which resulted in increased usage [6]. Undergraduates have been implicated in selftreating illnesses with prescription and nonprescription drugs including herbal products especially those that have enjoyed increased direct to customer (DTC) advertisement such as herbal supplements and HB [7]. Herbal bitters are usually poly-herbal liquid preparations which contain bitter herbs. There are other dosage forms, like capsules, tablets and tinctures which have been labeled by their manufacturers as bitters. They are commonly used as carminatives, aperitifs and to improve digestion. In Nigeria today, there is a preponderance of these products claiming to meet majority of the health need of the populace. The extent and pattern of use of $\mathrm{HB}$ in any population has not been studied to the best of our knowledge. Hence, the purpose of this study was to evaluate the extent of herbal bitter use among university students, pattern of use, self-reported indications and side effects experienced with these products and possible drugs that are concomitantly coadministered.

\section{EXPERIMENTAL}

This was a cross sectional study carried out in the University of Ibadan, Oyo state, Nigeria. It was undertaken in the ten halls of residence in the university since students of the same discipline were usually not paired together as roommates. The halls of residence are divided into several blocks with each block having an average of 56 rooms; and an average of four legal occupants per room. The study was carried out strictly adhering to the principles outlined in the most recent amendment of Helsinki declaration of 1964 [8].

Only bona fide, duly registered students who are legal occupants of the room and who were present in their rooms at the time of the survey and consented to take part in the study were allowed to fill the questionnaire. Participation was fully voluntary. Illegal occupants of the rooms, friends and visitors of the occupants were excluded from the study. The population statistics of the university was obtained from the planning unit of the university and the total number of students enrolled during the
$2009 / 2010$ session was 19,787 . From this, the sample size was determined to be 377 using the formula reported by $\mathrm{Hu}$ and Rosenberger [9].

The survey was carried out between the months of May and September, 2011. Questionnaires were distributed in the evenings when the majority of the students were expected to be in their hostels. Alternate rooms in each of the ten halls of residence were selected for the study, but when the legal occupants of a room were not available or the room is locked; the study continued with next room with legal occupants. Bona fide and legal occupant students, present in the rooms visited were approached, their consent sought and those who signified interest to participate in the study were administered the questionnaire. The last room visited was marked at the close of each day's survey for continuity. The questionnaires were retrieved from the students on the same day they were given.

Socio-demographic information including sex, age, marital status, level of education of the participants (current year of study) were obtained from the first section of the questionnaire. The other sections were designed to obtain data regarding the pattern of use of herbal bitters among participants, self-reported indications and side effects and participants' opinions on the use of two or more herbal bitters simultaneously and the long term use of $\mathrm{HB}$.

The pilot questionnaire had a total of 46 questions which was pre-tested among 30 students who lived off-campus and were randomly picked. Ambiguous questions were removed, and the option "others, please specify" was added to some of the answer choices for adequate responses. The result of the pilot test was not included in the final analysis and results. The final questionnaire was reviewed by two lecturers in the Faculty of Pharmacy and had a total of 39 structured questions. A total of 1000 questionnaires were administered and 977 recovered out of which 17 were rejected because important sections were not properly filled.

\section{Data analysis}

Data were analyzed with Statistical Package for Social Sciences, Window version 15.0. Descriptive statistics were used to evaluate the distribution of the participants' demographics. Pearson Chi-square statistics, Fisher's Exact test were used to detect associations between gender and self-reported indications and side effects experienced with herbal bitters. Relative risk ratio was used to identify gender associated self-reported side effects. Level of significance was set at $p<0.05$. 


\section{RESULTS}

The response rate was $96 \%$ and the mean age of the students was $22.07 \pm 3.77 \mathrm{yrs}$. Nine hundred and twenty $(95.8 \%)$ undergraduates and $40(4.2 \%)$ postgraduates participated in the study. Of these, $554(57.7 \%)$ were male and 406 $(42.3 \%)$ were female; $930(96.9 \%)$ were unmarried and $30(3.1 \%)$ were married, divorced or widowed. The prevalence of HB use among the students was $393(40.9 \%)$ with a decrease with increasing age and year of study. The list of the commonly used HB is provided in Table 1.

Most of the HB were packed as aqueous extracts in liquid dosage forms and used by students 381 (98.1\%), for various indications listed in Table 2. HB were recommended to users mostly by relatives $132(34.2 \%)$, friends $123(32.2 \%)$, and less likely by pharmacists $21(5.4 \%)$, physicians $14(3.6 \%)$ or nurses $11(2.8 \%)$. Ninety-nine participants (25.3\%) bought and used HB as a result of advertisement on print and electronic media.

Majority of the participants used these HB orally $324(82.4 \%)$ while few others applied it to the eyes/ears/nose $44(11.2 \%)$, on the skin 9 (2.3 $\%)$, on sores $4(1.0 \%)$, and as a gargle 4 (1.1 $\%)$. However, $86(22.1 \%)$ of the participants are long term (more than 12 weeks) users of HB. Some of the users of HB sometimes use two types of bitters simultaneously 15 (3.9\%). The main reason was that the combinations of two or more bitters work faster or better $9(31.0 \%)$. Only $183(21.7 \%)$ believed that the use of HB in pregnancy is safe and some of the married participants who use HB also give them to their children 13 (3.4\%).

Table 1: List of popular and frequently used herbal bitters among participants

\begin{tabular}{|c|c|c|}
\hline $\begin{array}{l}\text { Name of herbal } \\
\text { bitters }\end{array}$ & $\begin{array}{l}\text { Popularity of } \\
\text { bitters } \\
N=960\end{array}$ & $\begin{array}{l}\text { Frequently used } \\
\text { bitters (\%) } \\
\mathrm{N} \leq 395\end{array}$ \\
\hline Yoyo bitters $®$ & $836(87.1)$ & $293(74.7)$ \\
\hline Alomo bitters $®$ & $397(41.4)$ & $108(27.4)$ \\
\hline $\begin{array}{l}\text { Field's Swedish } \\
\text { bitters } ₫\end{array}$ & $379(39.5)$ & $62(15.7)$ \\
\hline $\begin{array}{l}\text { Nature's work } \\
\text { Swedish } \\
\text { bitters } ®\end{array}$ & $173(18.0)$ & $24(6.1)$ \\
\hline Evans bitters $®$ & $113(11.8)$ & $19(4.8)$ \\
\hline $\begin{array}{l}\text { Daily Living } \\
\text { bitters } ®\end{array}$ & $64(6.7)$ & $14(3.5)$ \\
\hline Kaka bitters $®$ & $20(2.1)$ & $6(1.5)$ \\
\hline U \& D bitters $®$ & $11(1.1)$ & $3(0.85)$ \\
\hline $\begin{array}{l}\text { Oroki herbal } \\
\text { mixture } ₫\end{array}$ & $9(0.9)$ & $6(1.5)$ \\
\hline Adams bitters ${ }^{\circledR}$ & $2(0.2)$ & $2(0.5)$ \\
\hline Super bitters® & $2(0.2)$ & $2(0.5)$ \\
\hline Poza bitters ${ }^{\circledR}$ & $1(0.1)$ & $1(0.25)$ \\
\hline
\end{tabular}

Table 2: Association between gender and self-reported indications for herbal bitters

\begin{tabular}{llll}
\hline Indication & Male & Female & Pearson Chi square \\
& F (\% within sex) & F (\% within sex) & P-value \\
\hline Cleanser & $88(40.2)$ & $62(38.8)$ & 0.778 \\
Blood purifier & $88(40.4)$ & $54(34.0)$ & 0.205 \\
Vigour & $57(25.0)$ & $16(9.8)$ & $0.000^{\circ}$ \\
Detoxifier & $49(22.4)$ & $27(17.0)$ & 0.197 \\
Indigestion & $48(21.1)$ & $36(21.8)$ & 0.855 \\
Anti-infective & $48(21.1)$ & $26(15.9)$ & 0.194 \\
Stomach ache & $48(21.6)$ & $33(20.6)$ & 0.814 \\
Improve libido & $39(17.9)$ & $2(1.3)$ & $0.000^{\circ}$ \\
Constipation & $33(15.2)$ & $18(11.3)$ & 0.277 \\
Rejuvenation & $32(14.0)$ & $6(3.7)$ & $0.001^{\circ}$ \\
To flatten tommy & $16(7.0)$ & $20(12.1)$ & 0.083 \\
Appetite stimulant & $16(7.0)$ & $4(2.4)$ & $0.041^{*}$ \\
Weight loss & $14(6.1)$ & $16(9.7 \%)$ & 0.190 \\
Stress relief & $14(6.2)$ & $2(1.2)$ & $0.015^{*}$ \\
Analgesic & $13(6.0)$ & $20(12.6)$ & $0.028^{*}$ \\
Soothe insect bite & $6(2.8)$ & $2(1.3)$ & 0.476 \\
Rashes & $3(1.4)$ & $0(0.0)$ & 0.266 \\
Toothache & $1(0.5)$ & $2(1.3)$ & 0.576 \\
Dysmenorrhea & $0(0.0)$ & $47(29.4)$ & $<0.001^{*}$ \\
\hline F & & & \\
\hline
\end{tabular}

$F=$ Frequency, ${ }^{*} p<0.05$ 
Side effects experienced by users of $\mathrm{HB}$ are listed in Table 3. Three participants $(0.9 \%)$ reported that $\mathrm{HB}$ had caused them a form of disability, though the nature was not mentioned and only one among these participants was consequently hospitalised. Participants, who had used HB before had used it with other classes of drugs including antimalarials 22 (6.3\%); haematinics 20 (5.7\%); multivitamins 18 (5.1\%); analgesics 16 (4.5\%); herbal supplements 13 (3.7\%); anti-infectives 10 (2.8\%); anti-tussives 7 $(2.0 \%)$; antacids 5 (1.4\%); anti-helminthics 3 (0.9\%); anti-ulcers 3 (0.9\%); anti-hypertensives $1(0.3 \%)$ and laxatives $1(0.3 \%)$.

Some participants 374 (42.4\%) opined that long term usage of HB (more than 12 weeks) was unsafe because it may cause numerous side effects $62(19.1 \%)$, may be hazardous to health $33(10.2 \%)$, may cause addiction after prolonged use $32(9.9 \%)$, liver damage 28 (8.6\%), toxin build-up 18 (3.1\%) and herbal remedies are not $100 \%$ pure $4(1.2 \%)$. Reasons adduced for safety in long term use (more than 12 weeks) were that $\mathrm{HB}$ are, safer than allopathic medicines 50 (38.8 \%), have detoxifying and cleansing effect 15 (11.6\%), prevent sickness 6 (4.7\%), reduce blood sugar and prevent diabetes 6 (4.7 $\%)$, boost immunity $3(2.3 \%)$ and maintain normal body functions $4(3.1 \%)$.

There was no significant difference between gender and type of HB used ( $p>0.5$ ), except in the case of Alomo bitters $®$ where a significant difference was observed between the male 89
$(82.4 \%)$ and female $19(17.6 \%)$ participants ( $p$ $<0.05)$. There were significant differences in gender for the use of $\mathrm{HB}$ for rejuvenation, vigour, stress relief and appetite stimulation ( $p<0.05$ ) (see Table 2). Male participants differ significantly from the female in experiencing the following side effects: excessive thirst, dizziness, ocular pain and headache $(p<0.05)$ (see Table 3).

Yoyo bitters ${ }^{\circ}$ was mostly used by the participants for weight loss 28 (93.3 \%), indigestion 72 (85.7\%), anti-infectives 56 (75.7 $\%)$ appetite stimulation $18 \quad(90.0 \%)$, dysmenorrhoea 44 (89.8\%) and as analgesic 26 $(78.8 \%)$. Alomo bitters $®$ was frequently used for the improvement of libido $38(92.7 \%)$ and for vigour $42(57.5 \%)$. Side effects such as dizziness 37 (60.7\%), epigastric pain 15 (62.5 $\%$ ) occurred more with Alomo bitters $\circledR$ use while loss of taste 57 (79.2 \%) was more common with Yoyo bitters ${ }^{\circ}$.

\section{DISCUSSION}

Self-treating illnesses begins with adolescents who are readily influenced by peer-pressure, family members and direct to customer (DTC) advertisements [10]. In this study, almost half of the participants who were mostly adolescents engaged in self-treating illnesses and other conditions with $\mathrm{HB}$ based on the recommendation of their friends and relatives. The use of herbs could relieve minor ailments that do not require prescription and cut down on

Table 3: Association between gender and self-reported side effects experienced with herbal bitters

\begin{tabular}{|c|c|c|c|c|c|}
\hline $\begin{array}{l}\text { Side effect } \\
\text { experienced }\end{array}$ & $\begin{array}{l}\text { Male } \\
\text { F (\% within } \\
\text { sex) }\end{array}$ & $\begin{array}{l}\text { Female } \\
\text { F (\% within } \\
\text { sex) }\end{array}$ & $\begin{array}{l}\text { Relative } \\
\text { risk } \\
\text { ratio } \\
\end{array}$ & $\begin{array}{l}95 \% \text { Confidence } \\
\text { interval }\end{array}$ & $\begin{array}{l}\text { Pearson Chi } \\
\text { square } \\
\text { p-value }\end{array}$ \\
\hline Dizziness & $49(22.0)$ & $12(7.5)$ & 2.930 & $1.612-5.326$ & $0.000^{*}$ \\
\hline Loss of taste & $46(20.6)$ & $26(16.1)$ & 1.277 & $0.826-1.976$ & 0.329 \\
\hline Nausea and vomiting & $22(9.7)$ & $19(11.7)$ & 0.830 & $0.465-1.482$ & 0.644 \\
\hline Epigastric pain & $18(8.0)$ & $6(3.8)$ & 2.143 & $0.870-5.278$ & 0.134 \\
\hline General weakness & $16(7.2)$ & $8(5.0)$ & 1.435 & $0.629-3.271$ & 0.514 \\
\hline Diarrhoea & $14(6.3)$ & $11(6.9)$ & 0.909 & $0.424-1.950$ & 0.972 \\
\hline Excessive thirst & $8(3.6)$ & $0(0.0)$ & - & - & $0.023^{*}$ \\
\hline Ocular pain & $8(3.6)$ & $0(0.0)$ & - & - & $0.023^{*}$ \\
\hline Headache & $6(2.6)$ & $0(0.0)$ & - & - & $0.042^{*}$ \\
\hline $\begin{array}{l}\text { Numbness (hands \& } \\
\text { feet) }\end{array}$ & $4(1.8)$ & $0(0.0)$ & - & - & 0.144 \\
\hline Stomach ache & $3(1.3)$ & $0(0.0)$ & - & - & 0.269 \\
\hline $\begin{array}{l}\text { Swelling of body } \\
\text { parts }\end{array}$ & $3(1.3)$ & $2(1.2)$ & 1.084 & $0.183-6.413$ & 1.000 \\
\hline Rashes & $2(0.9)$ & $0(0.0)$ & - & - & 0.511 \\
\hline Joint pain & $1(0.4)$ & $0(0.0)$ & - & - & 1.000 \\
\hline Menstrual irregularity & $0(0.0)$ & $4(2.4)$ & - & - & 0.030 \\
\hline
\end{tabular}


physician visits. Majority of participants in our study used HB for indications such as vigour, indigestion, stomach ache, constipation, rejuvenation and as appetite stimulants. This responsible self-treating is sometimes not without attendant risks; even over the counter (OTC) self-medication has been found to cause severe form of adverse drug reactions (ADRs) [11]. The use of HB for wrong indications such as weight loss remedy causes diarrhoea and diuresis as reported by participants; these could cause severe consequences such as dehydration or hypovolemic shock.

Label tags such as "These claims have not been evaluated by NAFDAC" is a mandatory statement on every pack of $\mathrm{HB}$ to dissuade people from irresponsible use of these products. Not only are HB sometimes used for wrong indications, they are also administered via wrong routes such as the ophthalmic application. About one-tenth of the students applied various HB products to the eye/ear/nose. The phytochemicals and excipients in HB may be corrosive to mucus membrane, thus, great caution should be exercised in administering these products via these routes until studies are available to support its use in order to avoid permanent damage to the mucus membrane, cornea or the ear drum. Ophthalmic preparations are sterile but this cannot be said for $\mathrm{HB}$, which are mostly unstandardized and may contain unquantifiable microbial load, posing danger to the eye/ear/nose when applied. Scanty evidence exists of the beneficial effect of traditional medicine in the treatment of eye conditions yet harmful effects have been reported [12].

Herbal bitters advertisements on print and electronic media also influenced about a quarter of the students into using these products. DTC advertisement of self-medication products appeal to ease of use, psychosocial enhancement, efficacy and safety [13]. In Nigeria, the regulation of DTC advertisement of HB is not strict. Peripatetic hawking of these products in commuter buses and market places is common in the country [14]. The preponderance of these products and the unchecked advertisements have led to the use of HB for indications that are conjecture of the user or group of users resulting in inappropriate use. Mainly, these products are indicated for indigestion, appetite stimulation and as carminatives but users tend to administer them for various reasons like weight loss, as antiinfectives, to cure chronic diseases, stress relief and for rejuvenation. These are unsubstantiated indications. The general belief is that these products are capable of multiple indications because of their poly-herbal nature. They are commonly referred to in the western part of the country in the local parlance as "gbogbo nise" literarily meaning "effective for all ailments".

Inappropriate use of $\mathrm{HB}$ includes its administration to children, concomitant administration with other medicines and taking two or more HB simultaneously. Less than onetwentieth of the students use combination of bitters simultaneously with the notion that it will work better and faster. The reason was that herbal medicines such as herbal bitters contain multiple components and when two similar products are used together, there could be a potentiation of pharmacological effects resulting in increased activity.

The use of HB with other allopathic medicines was also noticed in this study. Africans often supplement hospital prescriptions with recommendations from family members and traditional health practitioners in the hope of hastening recovery which may sometimes result in ADR and cause emergency admissions leading to increase morbidity and mortality [15].

Bitters were co-administered with antimalarial, anti-infectives, analgesics and herbal supplements. Herbs contain secondary metabolites such as flavonoids, tannins, saponins and coumarins that are inhibitors of important cytochrome $\mathrm{P} 450$ isoforms responsible for the metabolism of most drugs [16]. This interaction may potentiate the activity of the coadministered allopathic medicines and lead to toxic level of such drugs.

None of the side effects experienced by the study participants is listed on the product pack or the product inserts of the HB. Since there is no prior warning to the user, experiencing any of these side effects could make the user discontinue the use of the HB and thus aborting the supposed therapeutic benefit. Sometimes, users may tolerate some of the side effects that may be a warning signal for more troublesome ADR.

\section{Limitations of the study}

Reported indications and side effects could have been exaggerated as is common with selfreports. This study considered only the student population and not the entire university community. This may limit the generalisation of the findings to the general populace. However, the opinions and perception of students on herbal bitters use may be representative of students view in Nigeria. 


\section{CONCLUSION}

The co-administration of herbal bitters with allopathic medicines and the use of more than one herbal bitter at a time as reported in this study can be addressed by the appropriate health authorities through proper educational programmes. Furthermore, proper channel of reporting suspected side effects or adverse drug reactions to herbal bitters should be outlined in product inserts and direct-to-customer advertisement of HB should be scrutinised for contents that may encourage inappropriate use.

\section{ACKNOWLEDGEMENT}

The authors wish to express their appreciation to all the students who took part in this study.

\section{REFERENCES}

1. Falodun A. Herbal medicine in Africa - distribution, standardization and prospects. Res $J$ Phytochem 2010; 4: 156-161.

2. Oreagba IA, Oshikoya KA, Amachree M. Herbal medicine use among urban residents in Lagos, Nigeria. BMC Complement Altern Med 2011; 11: 117-124.

3. Osamor PE, Owumi BE. Complementary and alternative medicine in the management of hypertension in an urban Nigerian community. BMC Complement Altern Med 2010; 10(1): 36-44.

4. McCrea CE, Pritchard ME. Concurrent herb-prescription medication use and health care provider disclosure among university students. Complement Ther Med 2011; 19(1): 32-36.

5. Oguntade AE, Oluwalana IB. Structure, control and regulation of the formal market for medicinal plants' products in Nigeria. Afr J Tradit Complement Altern Med 2011; 8(4): 370-376.

6. Adegoju A. A rhetorical analysis of the discourse of advertising herbal medicine in southwestern Nigeria. Linguist. Online 2008; 33(1/08): 4-12.

7. Burak LJ, Damico A. College students' use of widely advertised medications. J Am Coll Heal J Ach 2000; 49(3): 118-121.

8. Williams JR. The Declaration of Helsinki and public health. Bull World Health Organ 2008; 86(8): 650652.

9. Hu F, Rosenberger WF. Sample Size Calculation. Theory Response-Adapt. Randomization Clin. Trials. John Wiley \& Sons, Inc. 2006; 91-104.

10. Afolabi AO. Factors influencing the pattern of selfmedication in an adult Nigerian population. Ann Afr Med 2009; 7(3): 120-127.

11. Gryzlak BM, Wallace RB, Zimmerman MB, Nisly NL. National surveillance of herbal dietary supplement exposures: the poison control center experience. Pharmacoepidemiol Drug Saf 2007; 16(9): 947-957.

12. Klauss $V$, Adala $H$. Traditional herbal eye medicine in Kenya. World Health Forum 1994; 15: 138-143.

13. Yusuff KB, Yusuf A. Advertising of OTC products in a Nigerian urban setting: Content analysis for indications, targets, and advertising appeal. J Am Pharm Assoc 2009; 49(3): 432-435.

14. Yusuff KB, Sanni AW. Itinerant vending of medicines inside buses in Nigeria: vending strategies, dominant themes and medicine-related information provided. Pharm Pr 2011; 9(3): 128-135.

15. Fakeye TO, Tijani A, Adebisi O. A survey of the use of herbs among patients attending secondary-level health care facilities in southwestern Nigeria. J Herb Pharmacother 2007; 7(3-4): 213-227.

16. Johnson WW. Cytochrome P450 inactivation by pharmaceuticals and phytochemicals: therapeutic relevance. Drug Metab. Rev 2008; 40(1): 101-147. 